\title{
Pragmatic failure revisited: Jaworski's (1994) study in a new light
}

\author{
Galina Shleykina a *(i) \\ a Miami University, Oxford, Ohio, 45056 USA
}

\begin{tabular}{l|l|l} 
Received 01 November 2020 & Received in revised form 18 December 2020 & Accepted 06 January 2021
\end{tabular}

APA Citation:

Shleykina, G. (2021). Pragmatic failure revisited: Jaworski’s (1994) study in a new light. Eurasian Journal of Applied Linguistics, 7(1), 303-315.

Doi: 10.32601/ejal.911399

\begin{abstract}
In the current conditions of globalization and the use of English as a lingua franca (ELF), the notions of pragmatic competence and appropriateness as well as pragmatic failure become of paramount importance to the language learners and instructors. The current article discusses these questions through an approximate replication of Jaworski's (1994) study of pragmatic failure in responses to English greetings by Polish English as a Foreign Language (EFL) students. The need for the replication arises from the lack of studies addressing pragmatic failure of EFL learners and the need to approach pragmatic behaviour of EFL learners in the conditions of ELF. The replication duplicates the methods of data collection and analysis of the original study but alters the native language (L1) of the participants and expands the study through the analysis of responses and the ratings. The data consists of Russian EFL learners' responses to the "How are you?" greeting question in the examination context. The results showed that Russian EFL learners achieve pragmatical success: the majority of the responses was rated as appropriate by the English native speakers. It is concluded that the original study's concern with teaching pragmatics should be applied and investigated in greater details focusing on ELF. Additionally, the notions of pragmatic competence and pragmatic failure need to be reevaluated and applied in the context of ELF.
\end{abstract}

(C) 2021 EJAL \& the Authors. Published by Eurasian Journal of Applied Linguistics (EJAL). This is an open-access article distributed under the terms and conditions of the Creative Commons Attribution license (CC BY-NC-ND) (http://creativecommons.org/licenses/bync-nd/4.0/).

Keywords: Pragmatic competence; pragmatic failure; greeting responses; ELF; EFL

\section{Introduction}

In the second language pragmatic research, the fundamental concept is pragmatic competence. It has been traditionally defined as contextually appropriate language use (see, e. g. Barron, 2003; Kasper,1998; Taguchi, 2009). Such an understanding has developed with time and in the current conditions of an increased communication between non-native English speakers (NNS) and the development and use of English as a Lingua Franca (ELF), pragmatic competence is viewed as a dynamic dialogic multi-dimensional construct - as "the ability to negotiate meaning in a flexible, adaptive manner and co-

\footnotetext{
* Corresponding author.

E-mail address: shleykg@miamioh.edu

http://dx.doi.org/10.32601/ejal.911399
} 
construct a communicative act" (Taguchi \& Ishihara, 2018, p. 82) and is defined broadly as "an understanding of how learners successfully participate in intercultural interaction" (Taguchi, 2017, p. 157). In such a view, the question of pragmatic failure in ELF needs to be addressed further. The current article attempts to view and conceptualize pragmatic failure in the light of ELF through the approximate replication of Jaworski's (1994) work.

In second language pragmatics, pragmatic failure is traditionally defined as "the inability to understand what is meant by what is said" (Thomas, 1983, p. 91) and is classified into two types - pragmalinguistic and sociopragmatic failure. Instances of such failures have been in the focus of researchers' attention for long and have been examined in a variety of speech acts. The most researched speech acts are requests and apologies, beginning with the pioneering study by Blum-Kulka and Olshtain (1984) and followed by many others (e. g. Cohen \& Olshtain, 1993; Economidou-Kogetsidis, 2011; Trosborg, 1995). Other studies analyzed pragmatic failure in the production of refusals (Beebe, Takahashi, \& Uliss-Weltz, 1990), greetings (Ebsworth et al., 1996; Shleykina, 2019), expressions of gratitude (Eisenstein \& Bodman, 1986), invitations (Rakowicz, 2009), and disagreement (Salsbury \& Bardovi-Harlig, 2001). The formulaic nature of many speech acts may cause challenges for language learners and may result in the wrong use of formulas (Kecskes, 2000), unnecessary extended elaboration (Blum-Kulka \& Olshtain, 1986; Edmondson \& House, 1991), or wrong formula delivery (House, 1996). This scholarship has shown that learners of English diverge from the native speakers (NS) of English in morpho-syntactic as well as socio-cultural speech acts characteristics, often resulting in pragmatic failure. In 1994, Jaworski contributed to the studies of crosscultural pragmatic failure and exemplified it by responses to English greetings. Today twenty-five years later - with the expansion of English as a foreign language (EFL) use, the development and practice of ELF in intercultural communication, increased superdiversity (Arnaut et al., 2015), and departure from the NS model orientation in teaching in general and in pragmatics in particular, it is important to replicate Jaworski's study and revisit and reconceptualize the notion of pragmatic failure (McGee, 2019). Such reconceptualization can help us understand pragmatic competence in intercultural communications and contribute to the investigation of pragmatics in ELF - the area which is yet insufficiently researched (Seidlhofer, 2011; Taguchi \& Ishihara, 2018).

\subsection{The original study}

In 1994, Jaworski examined the responses to the English greeting "How are you?" phrase produced by 72 advanced Polish EFL learners. He hypothesized that "Polish speakers of English will tend to fail pragmatically when they are greeted in English with the formulaic question How are you (doing)?, taking it as a non-formulaic enquiry about their actual well-being" (Jaworski, 1994, p. 43). Such assumption was based on the differences between greeting formulas in L1 (Polish) and L2 (English). In English, the phrase "How are you?" is a "phatic expression" (Malinowski, 1923, p. 315), which has a social function rather than an informative one and does not require literal understanding. It is a signal of an interlocutor's recognition, a necessary component of a social encounter (Berger \& Bradac, 1982; Leech, 1983), often a conversation opener, an "established 
conversational routine" (Wierzbicka, 1991, p. 132), and a friendliness, politeness and interest marker. In Polish, there are routinized greeting phrases such as "Jak leci?" ("How is it going?"), "Co tam (u ciebie) sychać?" ("What's interesting there with you?"), "Jak tam?" ("How it goes?"), "Jak tam sie wiedzie?" ("How it goes with you?"), and other formulaic phrases beginning with the adverbial pronoun jak (how) or the pronoun co (what) (Jakubowska, 1998; Jaworski, 1994) that can map directly onto the English phrase "How are you?". However, in Polish they are "less formulaic" (Jaworski, p. 43) than in English and their occurrence and frequency depend on the context and contextual variables.

These differences have led to the hypothesis that L2 Polish learners would fail pragmatically while responding to English "How are you?" In order to test it, the following experiment was conducted. The examiner asked the students taking an English examination at Adam Mickiewicz University in Poznań the question "How are you (doing) (today)?" as a part of greeting social routine. The students' responses were immediately written down by the examiner and after the exam, were evaluated by NS raters for their pragmatic appropriateness. It was found that the learners fail to respond appropriately to the English greeting and demonstrate pragmalinguistic and sociopragmatic failure as well as "insufficient degree of automatization" (Jaworski, 1994, p. 53) in their responses. Jaworski concluded that although "uniformity and invariance" (p.53) should not be required of language learners, the awareness of appropriate phatic communication and pragmatic routines should be increased.

\section{Method}

In order to observe the current and ongoing changes in the ecology of the English language and to see how we can define pragmatic competence and apply pragmatic norms of appropriateness in the current conditions of ELF, it seemed necessary to replicate the original study. Additionally, the replication was motivated by the necessity to explore the notion of pragmatic failure in ELF as well as to revisit the question of pragmatic competence evaluations and the role of NSs in such evaluations. Such discussions are still underrepresented in research (Taguchi \& Ishihara, 2018) and are needed to advance our understanding of the pragmatics of ELF.

The approximate replication reported in the remainder of this paper duplicates the methods of data collection and analysis of Jaworski's original study, while altering the participants' L1 and extending the interpretation and analysis. Following the original research, the replication study examines the greeting responses to the phrase "How are you?" produced by Russian EFL learners in the examination context. The hypothesis is that Russian EFL learners would demonstrate pragmatic failure in their responses to the greeting "How are you?" as rated by the NS judges.

As in the original study, the data was collected during English oral exams at a State University in Russia. The participants of the study were 85 students majoring in English. Students with this major usually take a variety of English courses, for example, grammar, conversation, reading, listening, translation, and country studies, 
many of which are taught in English. At the end of each semester, students take mandatory examinations. They can be written - project-based or essay-type, - or oral. For this study, oral examinations in four aspects of English were chosen: Conversational English, Practical English, Business English, and Home Reading. In these classes, students take the examinations individually: they enter the classroom one by one and are examined by one instructor. The examinations are held in English, and students are expected to speak English throughout the whole exam. Switching to L1 or asking clarifying questions in L1 are considered as flaws in the answer and influence the evaluation negatively. These context specifications are the same as in the original study.

As in Jaworski's study, when a student entered the classroom for the exam, the instructor greeted him/ her with a phrase "How are you?/ Hello! How are you (doing) (today)?" The instructor listened to the student's response and immediately wrote it down on paper or filled in a response sheet (Table 1). Since there were different kinds of papers on the instructor's desk and the instructor was making notes during the exam, the students did not pay attention to the instructor writing something down at the beginning of the exam and were unaware that their responses to the greeting were recorded. This was done on purpose since the answers should be natural. Similar to the original, the responses to "How are you?" were not treated as part of the examination and did not influence in any way the final evaluation of the students' speaking abilities.

Table 1. Exam greeting response sheet

Course title

Student \# response

Comments

Similar to Polish, the question "How are you?" is not universal in Russian. The Russian language has several phrases corresponding to the English "How are you?": "Как дела?" (“Kak dela?" - "How are things?”), “Как живешь/ живёте?” (“Kak zhivesh/ zhivyote?” "How do you sg/ you pl live?), and “Как жизнь?" ("Kak zhiz'n'?" - "How is life?"). Such questions are ritualized; however, the ritualized nature is different from English. First, they not universally asked and depend on social variables of age, distance, and power. They are typically asked among friends, close people, or in-group participants, in other words, when there is a rapport and close relationships between participants or such rapport and relationships are being established. The response is usually neutral, for example, "OK," "All right" or downgraded "Not so good," "Bad," or "Don't ask". Moreover, such responses require some elaboration which often leads to a further talk. Of course, this is not to say that "Kak dela?" always leads to an extended conversation. The response might be brief depending on the context and such factors as age, distance between interlocutors, and social status. In the context of the current study, a professor at the examination would rarely, if ever, ask it. As we will see in the data, several respondents 
were puzzled by the question and several repeated it, as if asking for confirmation of the question.

Following the original study, the students' responses were evaluated by the NSs of English - five graduate students at a North American university. The same 5-point rating scale was used: 1 - inappropriate, 2 - bad, 3 - somewhat OK, 4 - good, 5 - native-like. The mean rating between 1 and 5 for the responses was calculated. The raters wrote comments on their ratings and explained them. In the cases when the rating or the explanation was not clear, the raters were informally interviewed. Unlike in the original study, in the replication, the judges had a training session before the rating procedure. The purpose and the setting of the study were explained, the raters became familiar with the pragmatic concepts, rating scale and assessing criteria, reviewed examples, and practiced doing the ratings. Such a training was performed to ascertain that the raters are familiar with the concepts of pragmatic appropriateness and pragmatic failure, understand them, and are able to explain their ratings given the background

\section{Results}

Jaworski found that $45.8 \%$ of the responses were rated as less than "somewhat OK," in other words were "bad" or "inappropriate" with the mean rating less than 3 ; $25 \%$ were rated between "somewhat OK" and "good" with the mean rating between 3 and 3.99; 29.9\% - "good" or close to "native like" with the mean rating 4 and higher. Jaworski's original hypothesis that the Polish learners of English "show difficulty in recognizing and using formulaic expressions in greetings (p. 53) - was supported.

In the replication, $8.2 \%$ (seven responses) were rated as "bad" or "completely inappropriate" (the mean less than 3); 21.2\% (18 responses) - "somewhat OK" (the mean 3-3.99); and 70.6\% (60 responses) - "good" and "native-like" (the mean 4 and higher). In the latter group, $38.3 \%$ (23 responses) - native-like and completely appropriate (the mean 5) and 61.6\% (37 responses) - good (the mean 4-4.99). The hypothesis of the replication - the Russian leaners of English would demonstrate pragmatic failure in the responses to "How are you?" as rated by the NS judges - was not supported.

The majority of responses (70.5\%) in the replication was rated as native-like or good and appropriate given the context. The common pattern in the responses was a positive adjective and a thanking phrase, such as "Fine/ not bad/good, thank you" or a positive adjective, thanking phrase, and reciprocal question such as "Fine, thank you, and you?". The participants interpreted "How are you?" as a part of a social routine and gave a routinized formulaic answer.

The opposite end - the responses which were rated as "bad" or "inappropriate" include seven responses (8.2\%). The first "bad" or "inappropriate" answer was no response to the greeting question: three students (3.5\%) out of 85 did not respond to the question and completely ignored it. In Jaworski's data, the number was 10 out of $72(13.8 \%)$. Due to the "lesser obligation of occurrence of semantically equivalent in 
Polish" (Jaworski, p. 50), the Polish students did not perceive the greeting as such and ignored it. In the similar vein of lesser formulaicity of the Russian phrase "Kak dela?", three students in the replication transferred L1 pragmatic norm to their L2 production. They did not anticipate "How are you?" as a greeting and disregarded it. The absence of response and silence as an answer to "How are you?" was treated as inappropriate by the raters. The second answer that got low rating was one student's response "I'd rather not say." Giving such an answer, the students perceived "How are you?" as a genuine question about the well-being and answered it in a way that was interpreted as rude by the raters: two raters evaluated it as " 2 - bad" and three as " 1 - inappropriate", with the mean rating being 1.4 . The last three cases of low ratings are spontaneous remark which come from confusion or mishearing of the question. One student said her name as a response; the second student answered "That's right," perhaps meaning "Alright;" and the third said "So" which was interpreted by the raters either as misunderstanding or mispronunciation of "so-so," "unfinished phrase," and "something inarticulate." Using Thomas's (1983) terminology, these responses may be interpreted as blurts - slips of the tongue which represent "a temporary lapse by a normally pragmatically competent person" (p. 95). Such confusion could be caused by examination anxiety and stress. Additionally, the confusion demonstrated that such a question was not anticipated by the students and was not a part of social contextual routine of greeting in the students' repertoire.

The answers in the middle - with ratings between 3.99 and 3 -include a number of categories. First, several students gave elaborate answers and talked about problems with their classes, "tons of homework," and so on. Three raters considered such answers as completely appropriate in the given context and gave high ratings. However, for the two other raters these answers were inappropriate. One of the raters explained that telling the instructor about problems the student is having is completely inappropriate and sounds as complaining or as referencing to something else which is more important than the examination. Another category of the answers was references to examination anxiety: responses such as "nervous," "worried," "I'm shaking," "scared," or "I'm very nervous. I think I will not pass." Four judges rated such answers as appropriate in the given situation. For one rater, however, such responses were inappropriate in the context and unacceptable as a response to the instructor's greeting since they suggested student's nervousness due to the unpreparedness for the exam. The next category that the raters did not agree upon unanimously was negative responses such as "Not good," "Awful," and "So-so." For some raters, such responses were contextually appropriate considering the psychological conditions and emotional state of students. For other raters, such negative responses were inappropriate since they lead to the question "Why?" or in Sack's (1975) terminology, a "diagnostic sequence" (p. 70), and such discussions are not appropriate and not necessary during an examination (according to a contextual "system of regulations" which determines "whether the asker can handle such information, and to control his answer by reference to that determination" (Sacks, p. 73)). Lastly, the presence of introductory words, discourse markers, and 
conversational fillers such as "Well, fine," "I think I'm fine," and "I hope I'm fine" negatively influenced the ratings. Such phrases add hesitations which, according to the raters, are not appropriate in responding to "How are you?". However, one rater treated answers "I think I'm fine," "I hope I'm fine," and "Hm. It depends on my test here" as humorous - to establish rapport and lower the anxiety - and appropriate in the context of a small talk prior to the examination.

In total, the results differ significantly from Jaworski's. Two thirds of the responses were rated as good and appropriate, indicating that the formulaic language use of the Russian learners of English was evaluated as acceptable.

\section{Discussion}

The overall goal of the English classes for the English majors in Russian universities is to prepare them to become specialists in the English language and international communication. These courses prepare students to communicate not only and not necessarily with NSs of English but also, and mainly, with other NNSs under the conditions of ELF. Thus, the production of speech acts in general and responses to greetings in particular should be viewed considering the pragmatics of ELF. In such a context of ELF, the new definition of pragmatic competence is applied. Pragmatic competence is viewed as a dynamic phenomenon which includes negotiations of meaning, rapport building, problem-solving, and conversation management (Taguchi \& Ishihara, 2018), negotiating learners' identity and agency, and further collaboration in dialogues (Canagarajah, 2014). Analyzing the responses to the 'How are you?' greeting questions through the above features of pragmatic competence, we can reevaluate the notion of pragmatic failure in its traditional definition (Thomas, 1983). Similar to pragmatic competence in ELF, the concept of pragmatic failure should be viewed as a dynamic phenomenon which is flexible and adaptive to the immediate context and includes joint negotiation, management, and construction of meaning of a speech act through chosen conversational strategies.

Applying this reconceptualization of pragmatic competence and pragmatic failure to the results of the replication, we can suggest the following. First, the answers which were rated low - no response to the greeting, declared unwillingness to communicate in the phrase "I'd rather not say," and impetuous remarks - do not represent pragmatic failure per se and should be viewed through the prism of the specific context of the examination and negotiations and mutual conversational strategies applied in this context, including the remarks of the examiner and any follow-up conversation. Additionally, the individual characteristics of the students-respondents are important as well. As Ishihara (2018) notes, "in intercultural exchanges, interactants' pragmatic behavior can be interpreted as a manifestation of their individual character rather than as the artifact of limited communicative competence in the L2" (n. p.). Such interpretation can specifically explain lack of responses to the greeting and the atypical response by drawing attention to the features of the 
students' characters and their behaviour and not necessarily lacking pragmatic competence or pragmatic failure.

Second, in the analysis of the responses in the middle rating category - "somewhat OK," we should also carefully apply the contextual variables and individual respondents' features and look at the responses through the prism of negotiations of meaning and achieving a common goal. This is especially important in the instances where the agreement between raters was not high. Those instances include responses with repetition of the greeting (for example, "How am I? I'm good. How are you?), or self-corrections and pauses. Some raters treated them as completely appropriate in the given context, whereas other raters considered such responses inappropriate. Another example of raters' disagreement is the responses with negative adjectives, for example "Awful" or "Not good". In such instances, in addition to considering the immediate needs of the interlocutors in the examination context and the individual style of the respondents and their creativity (Kecskes, 2019), we should also look into the perlocutionary effect of the response to the greeting, in other words, into the effect it produces on the interlocutor - the examiner in our case, and what kind of a conversational development follows (Schnurr \& Zayts, 2013).

An additional layer to consider in the analysis of the responses is the transfer of L1 sociopragmatic norms, which goes in line with the traditional approach to the analysis of pragmatic appropriateness in speech acts (see, for example, Gass \& Neu, 1996; Kasper,1992). In the case of Russian, such norms include preference for directness and honesty in the responses and relative lack of mitigation (Larina, 2009). For example, in the response "How am I? Well, could be better," the student first, repeats the question, which itself could be an indicator of perceiving the greeting as a genuine question, and second, gives a non-formulaic honest answer. Such transfer of L1 norms - giving a sincere answer instead of a formula, was inappropriate for some NS raters and appropriate for the others, giving the examination context.

In sum, if we approach pragmatic competence not as a static and a given constant but as a negotiation and constant development with the ultimate goal of achieving effective communicative result, then the instances of "pragmatic failure" should also be viewed in this paradigm of negotiation and collaboration in the conversation. Specifically in the context of our experiment, pragmatic failure becomes more of a problem-solving and "rapport management" (Ishihara, 2018) instrument rather than 'failure' per se and pure form-function-context relationship, linguistic deficiency, or limitation in the language production.

An important question of teaching pragmatics in EFL context arises here. Pragmatic instruction in the EFL context in Russia is historically limited and is not the major goal in the English classes either for English university majors or nonmajors. Some formulas and speech acts might be taught, but, as one of the students mentioned in an informal interview after the replication experiment, pragmatic rules are not discussed explicitly; teachers mention them in passing and do not focus on details. Considering such a context, it seems necessary to reevaluate the approach to 
teaching pragmatics not only for the purposes of appropriateness and avoidance of being rude and offensive and developing negative stereotypes and marginalization, but also and more importantly for the purposes of international communication between speakers of different L1s and representatives of different cultures with the accent on managing conversations and negotiating and constructing meanings.

Lastly, an important consideration which needs to be addressed is the use of NS raters in assessing pragmatic competence. With the move away from the strict adherence to the NS norms in teaching pragmatics and focusing on contextual appropriateness and effective communication (Taguchi \& Ishihara, 2018), the use of NS raters in the assessment of pragmatic competence should be reevaluated. The raters, if used, should undergo a training, and should be explained the concepts of pragmatic competence, appropriateness, and failure. Instead of NS norms, the notion of multicompetence (Cook, 1999, 2016), and the idea of developing procedural knowledge (the how) instead of propositional (the what) (Canagarajah, 2014) can be applied. As an alternative to the NS concept, the term "an expert ELF user" (House, 2003, p. 150) is offered. Additionally, an "in-between style of interaction" (House, 2003, p. 148-150) in pragmatics is created on the basis of dialogicity and heterogeneity of sources or negotiating "hybrid pragmatics" (Murray, 2012, p. 4) considering the immediate purposes of the conversation and mutual agreement of the interlocutors and equipping learners with "pragmatic toolkit" (Murray, p. 7) of strategies appropriate with a particular interlocutor in the particular context.

Besides, sociopragmatic variability and subjectivity of raters add complexity to the analysis. The data in the current study demonstrates this idea. Several responses in the current data and in Jaworski's study coincide word for word; however, they get different ratings. For example, the response "I'm fine" gets a mean rating 3.25 in the original study but 4.8 in the replication. The response "Fine, thanks" has mean ratings 4.25-4.5 and 5 respectively. Several responses are very similar but still are rated inconsistently: "I am trembling" in Jaworski's study has mean rating 2 and "I am shaking" in the present study - 3.2; "Well, OK, thank you" -2.75 and "Well, fine, thank you" - 4.2 respectively. Further investigation of idiosyncrasies of raters and variability of NS language usage is, as mentioned in the original "by itself an interesting topic of investigation" (Jaworski, 1994, p. 54) and is necessary to interpret the discrepancies in the results.

In the present study, as noted above, the raters explained their rationale for each rating, and, as shown, their understanding of appropriateness was quite different. This is in agreement with previous studies, which showed that despite the training and the agreement upon the criteria, raters often bring their individual as well as socially variable values and beliefs into the assessment (Brown, 2003; Ishihara, 2013; Walter, 2007). As Taguchi (2011) demonstrated, NS raters with different cultural backgrounds, personal experiences, and individual features vary greatly in their approaches to pragmatic standards in ratings. They consider various dimensions when evaluating NNS performance - rules of politeness, politeness markers, vocabulary, word order, non-linguistic features, and weight them differently; 
moreover, they rely on their personal experience and project the context and the responses to themselves.

Lack of uniformity in the current data can be illustrated by the following examples. In the replication, one rater was rather severe in the ratings and said that the only appropriate response was positive adjective plus thanking. Lack of the thanking phrase was considered rude and responses "Fine" were rated as a 4. Another rater in the replication said that the students should use "adaptive" language with those who have higher status, power and influence - that is the examiner, and thus, they cannot use humorous language and jokes. Neither can they produce answers that encourage further questions. Moreover, the same rater said that the students should be very polite and cautious to demonstrate their inferior status. This contradicts the other raters who considered negative answers appropriate and the use of humor acceptable in the given context and supports the research on raters' variability and subjectivity (Taguchi, 2011).

In sum, the use of NS raters should be approached with careful considerations as the NS model should not be considered the "norm", and besides, sociolinguistic and sociopragmatic variability and subjectivity of raters is high even after the training.

\section{Conclusions}

This study - an approximate replication of Jaworski's study of the Polish learners of English responses to the greeting "How are you?" - was motivated by the relevance and importance of the topic as well as the necessity to reexamine the notion of pragmatic failure in the current conditions of ELF. The new population - Russian learners - showed a significantly lower percentage of pragmatic failure as rated by the trained NSs. Two thirds of the responses were rated as appropriate and sufficiently routinized and formularized. It is argued that those examples which were rated as "failure" or as "somewhat OK" should not be treated as failure per se or a communicative limitation. Rather, all responses should be viewed in their dynamics as negotiation of meaning and appropriateness in a specific context and as communicative collaboration between interactants, and the integrated approach to the analysis of L2 speech acts through pragmatics, discourse, and social interaction (Taguchi \& Roever, 2017), and conversational analysis (CA) can be applied.

The author acknowledges several limitations in regards of the replication methodology of the study. The differences between language pairs, between types of participating students and raters, and the rating procedure itself do exist. Additionally, the differences of the broad socio-political contexts between the original and the replication are significant. All of those aspects could have influenced the results. 
The original study and its replication have serious pedagogical implications. They encourage us to move in the direction of teaching strategies for effective intercultural communication. In teaching of pragmatics, the focus should be made on negotiation strategies rather than rigid speech acts or fixed norms. In order to enhance pragmatic and communicative competence of learners, it is necessary not only to introduce speech acts in different contexts and include explanations and extensive comments into the curriculum but also to incorporate teaching of conversational structures such as adjacency pairs in greeting - responding and strategies such as adjustments, avoidance, asking for repetition, and the like. In EFL and ELF teaching, it is essential to explain the importance of using these strategies and well as appropriate speech acts in order to achieve communicative goals and successful intercultural interaction.

\section{Acknowledgements}

I would like to thank the anonymous reviewers for their thoughtful comments and suggestions.

\section{The Conflict of Interest Statement}

In line with the statement of Committee on Publication Ethics (COPE), I hereby declare that I had no conflicting interests regarding any parties of this study.

\section{References}

Arnaut, K., Blommaert, J., Rampton, B., \& Spotti, M. (Eds.) (2015). Language and superdiversity. New York, NY: Routledge.

Barron, A. (2003). Acquisition in interlanguage pragmatics: Learning how to do things with words in a study-abroad context. Philadelphia, PA: John Benjamins.

Beebe, L. M., Takahashi, T, \& Uliss-Weltz, R. (1990). Pragmatic transfer in ESL refusals. In R.Scarcella, E. Andersen, \& S. D. Krashen (Eds.), On the development of communicative competence in a second language (pp. 55-73). New York: Newbury House/Harper Collins.

Berger, C. R., \& Bradac, J. J. (1982). Language and social knowledge. London: Edward Arnold Publishers Ltd.

Blum-Kulka, S., \& Olshtain, E. (1984). Requests and apologies: A cross-cultural study of speech act realization patterns (CCSARP), Applied Linguistics, 5 (3), 196213, https://doi.org/10.1093/applin/5.3.196

Blum-Kulka, S., \& Olshtain, E. (1986). Too many words: Length of utterance and pragmatic failure. Studies in Second Language Acquisition, 8 (2), 165-179.

Brown, A. (2003). Interviewer variation and the co-construction of speaking proficiency. Language Testing, 20 (1), 1-25.

Canagarajah, S. (2014). In search of a new paradigm for teaching English as an international language. TESOL Journal, 5 (4), 767-785.

Cohen, A. D. \& Olshtain, E. (1993). The production of speech acts by EFL learners. TESOL Quarterly, 27 (1), 33-56.

Cook, V. (1999). Going beyond the native speaker in language teaching. TESOL Quarterly 33 (2), 185-209. 
Cook, V. (2016). Where is the native speaker now? TESOL Quarterly, 50 (1), 186-189.

Ebsworth, M. E., Bodman, J. W., \& Carpenter, M. (1996). Cross-cultural realization of greetings in American English. In S. M. Gass \& J. Neu (Eds.), Speech acts across cultures (pp. 89-107). Berlin: Walter de Gruyter.

Economidou-Kogetsidis, M. (2011). "Please answer me as soon as possible": Pragmatic failure in non-native speakers' e-mail requests to faculty. Journal of Pragmatics, 43, 3193-3215.

Edmondson, W. \& House, J. (1991). Do learners talk too much? The waffle phenomenon in interlanguage pragmatics. In R. Phillipson, E. C. Kellerman, L. Selinker, M. SharwoodSmith, \& M. Swain (Eds.), Foreign/ second language pedagogy research: A commemorative volume for Claus Faerch (pp. 273-287). Clevedon: Multilingual Matters.

Eisenstein, M., \& Bodman, J. W. (1986). I very appreciate: Expressions of gratitude by native and non-native speakers of American English. Applied Linguistics, 7 (2), 167-185.

House, J. (1996). Developing pragmatic fluency in English as a foreign language: Routines and metapragmatic awareness. Studies in Second Language Acquisition, 18, 225-252.

House, J. (2003). Teaching and learning pragmatic fluency in a foreign language: the case of English as a lingua franca. In A. Martínez-Flor, E. Usó-Juan, \& A. Fernándes Guerra (Eds.), Pragmatic competence and foreign language teaching (p. 133-160). Castelló de la Plana: Publicacions de la Universitat Jaume I.

Gass, S. M. \& Neu, J. (Eds.) (1996). Speech acts across cultures: Challenges to communication in a second language. Berlin/ New York: Mouton de Gruyter.

Ishihara, N. (2018). Intercultural pragmatic failure. In J. I. Liontas, T. I. Association, \& M, Delli-Carpini (Eds.), The TESOL Encyclopedia of English Language Teaching. John Wiley \& Sons.

Ishihara, N. (2013). Teacher-based assessment of L2 Japanese pragmatics: Classroom applications. In S. Ross \& G. Kasper (Eds.), Assessing second language pragmatics (pp. 120148). New York, NY: Palgrave Macmillan.

Jakubowska, E. (1998). Greetings and farewells contrastively viewed. Linguistica Silesiana, 1 (1), 87-98.

Jaworski, A. (1994). Pragmatic failure in a second language: Greeting responses in English by Polish students. International Review of Applied Linguistics in Language Teaching, 32, 4155.

Kasper, G. (1998). Interlanguage pragmatics. In H. Byrnes (Ed.), Learning foreign and second languages: Perspectives in research and scholarship (pp. 183-208). New York, NY: The Modern Language Association of America.

Kasper, G. (1992). Pragmatic transfer. Interlanguage Studies Bulletin (Utrecht), 8(3), 203231. doi.org/10.1177/026765839200800303

Kecskes, I. (2000). Conceptual fluency and the use of situation-bound utterances. Links \& Letters, 7, 145-161.

Kecskes, I. (2019). Linguistic creativity in ELF. In English as a lingua franca: The pragmatic perspective (pp. 45-68). Cambridge: Cambridge University Press.

Larina, T. (2009). Kategoria vezhlovosti i stil' kommunikatsii. (Category of politeness and style of communication). Moskva: Rukopisnye pamyatniki drevnei Rusi.

Leech, G. N. (1983). Principles of pragmatics. London: Longman.

Malinowski, B. (1923). The problem of meaning in primitive languages. In C.K. Ogden \& I.A. Richards (Eds.), The meaning of meaning (pp. 296-336). New York, NY: Harcourt, Brace and World.

McGee, P. (2019). Cross-cultural pragmatic failure. Training, Language and Culture, 3 (1), 73 84. doi: $10.29366 / 2019$ tlc.3.1.5 
Murray, N. (2012). English as a lingua franca and the development of pragmatic competence. ELT Journal, 1-9. doi: 10.1093/elt/ccso16

Rakowicz, A. (2009). Ambiguous invitations: The interlanguage pragmatics of Polish English language learners. (Doctoral dissertation). Retrieved from ProQuest, UMI Dissertations Publishing. (3346268)

Sacks, H. (1975). Everyone has to lie. In M. Sanches \& B. G. Blount (Eds.), Sociocultural dimensions of language use (pp. 57-80). New York, NY: Academic.

Salsbury, T., \& Bardovi-Harlig, K. (2001). "I know you mean, but I don't think so:" Disagreements in L2 English. In L. F. Bouton (Ed.), Pragmatics and language learning, Vol. 10. (pp. 131-151). University of Illinois, Urbana-Champaign: Division of English as an International Language.

Schnurr, S., \& Zayts, O. (2013). "I can't remember them ever not doing what I tell them!": Negotiating face and power relations in 'upward' refusals in multicultural workplaces in Hong Kong. Intercultural Pragmatics, 10, 593-616.

Shleykina, G. (2019). The interlanguage pragmatics of greetings. Beyond Words, 7 (1), 43-60.

Seidlhofer, B. (2011). Understanding English as a Lingua Franca. Oxford: Oxford University Press.

Taguchi, N. (2017). Interlanguage pragmatics. In A. Barron, P. Grundy, \& G. Yueguo (Eds.), The Routledge handbook of pragmatics (pp. 153-167). Oxford/ New York: Routledge.

Taguchi, N. (2009). Pragmatic competence in Japanese as a second language: An introduction. In N. Taguchi (Ed.), Pragmatic competence (pp.1-18). Berlin: Mouton de Gruyter.

Taguchi, N. (2011). Rater variation in the assessment of speech acts. Pragmatics, 21 (3), 453471.

Taguchi, N. \& Ishihara, N. (2018). The pragmatics of English as a lingua franca: Research and pedagogy in the era of globalization. Annual Review of Applied Linguistics, 38, 80-101.

Taguchi, N. \& Roever, C. (2017). Second language pragmatics. Oxford, UK: Oxford University Press.

Thomas, J. (1983). Cross-cultural pragmatic failure. Applied Linguistics, 4 (2), 91-112.

Trosborg, A. (1995). Interlanguage pragmatics: Requests, complaints and apologies.

New York: Mouton de Gruyter.

Walter, S. (2007). A conversation-analytic hermeneutic rating protocol to assess L2 oral pragmatic competence. Language Testing, 24 (2), 155-183.

Wierzbicka, A. (1991). Cross-cultural pragmatics: The semantics of human interaction. Berlin/New York: Mouton de Gruyter.

\section{Copyrights}

Copyright for this article is retained by the author(s), with first publication rights granted to the Journal. This is an open-access article distributed under the terms and conditions of the Creative Commons Attribution license (CC BY-NC-ND) (http://creativecommons.org/licenses/by-nc-nd/4.0/). 